Keywords: sexual toxicity; prostate cancer; external beam radiation therapy; high-dose rate brachytherapy; prostatectomy; patient-reported outcomes

\title{
Patient-reported sexual toxicity after radiation therapy in long-term prostate cancer survivors
}

\author{
C E Olsson ${ }^{* 1,2}$, D Alsadius ${ }^{3}$, N Pettersson ${ }^{4}, \mathrm{~S}$ L Tucker ${ }^{5}$, U Wilderäng $^{3}$, K-A Johansson ${ }^{4}$ and G Steineck ${ }^{3,6}$ \\ ${ }^{1}$ Regional Cancer Centre West, Region Västra Götaland, Gothenburg, Sweden; ${ }^{2}$ Department of Radiation Physics, The \\ Sahlgrenska Academy, Gothenburg University, Gothenburg, Sweden; ${ }^{3}$ Division of Clinical Cancer Epidemiology, Department of \\ Oncology, The Sahlgrenska Academy, Gothenburg University, Gothenburg, Sweden; ${ }^{4}$ Department of Medical Physics and \\ Biomedical Engineering, Sahlgrenska University Hospital, Gothenburg, Sweden; ${ }^{5}$ Department of Bioinformatics and Computa- \\ tional Biology, The University of Texas MD Anderson Cancer Center, Houston, TX, USA and 'Division of Clinical Cancer \\ Epidemiology, Department of Oncology-Pathology, Karolinska Institutet, Stockholm, Sweden
}

Background: To present an overview of patient-reported sexual toxicity in sexually active long-term prostate cancer survivors treated with radiation therapy.

Methods: We used patient-reported outcomes from a study-specific questionnaire surveying symptoms after prostate cancer radiation therapy. Data from 518 men treated at the Sahlgrenska University Hospital in Sweden from 1993 to 2006 were analysed. The men had undergone primary or salvage external beam radiation therapy (EBRT) or EBRT combined with high-dose rate brachytherapy (BT). We also used information from 155 non-treated reference men from the general population with no history of prostate cancer, matched for age and residency.

Results: Median time from treatment to follow-up was 5 years (range: 1-14 years). Among the 16 investigated symptoms on erectile function, libido, orgasm, and seminal fluid, 9 symptoms in the primary EBRT group and 10 in both the salvage EBRT and the EBRT + BT groups were statistically significantly more prevalent in survivors than in reference men. Erectile dysfunction was influenced by both age and time to follow-up, whereas symptoms relating to orgasm and seminal fluid were influenced by time to follow-up only. Not being sexually active was almost one and a half times as common in survivors as in reference men.

Conclusions: The presented symptom profiles can help to develop personalized therapy for prostate cancer through a better understanding of which radiation-induced toxicities to be addressed in the clinic and can also assist in identifying suitable interventions for existing symptoms.

Modern prostate cancer treatments often lead to successful outcomes with respect to local tumour control and long-term survival (Budaus et al, 2012; Resnick et al, 2013). Radiation therapy has an important role in this regard as it is an excellent treatment option for localized disease. With current means to plan and deliver radiation therapy, the number and severity of late radiation-induced toxicities have been reduced for many patients. The radiation oncology community is, therefore, approaching the situation where it is time to also turn focus towards patientreported lower-grade toxicities to improve quality of life for survivors. Unfortunately, there is limited information about late lower-grade toxicities associated with prostate cancer irradiation, particularly for symptoms related to sexual dysfunction.

Assessing sexual dysfunction after radiation therapy is challenging. Patients may experience such symptoms for reasons other than those attributable to the treatment. Anxiety and depression

*Correspondence: Dr C Olsson; E-mail: caroline.olsson@oc.gu.se

Received 16 February 2015; revised 14 June 2015; accepted 26 June 2015; published online 4 August 2015

(c) 2015 Cancer Research UK. All rights reserved 0007-0920/15 
(De Sousa et al, 2012), diabetes mellitus (Roach et al, 2010; Budaus et al, 2012; Hoppe et al, 2012; Magli et al, 2012; Kerns et al, 2013), hormonal treatments (Roach et al, 2010; Budaus et al, 2012; Haugnes et al, 2012; Magli et al, 2012; Incrocci and Jensen, 2013; Kerns et al, 2013), and older age (Mirza et al, 2011; Budaus et al, 2012; Keller et al, 2012; Incrocci and Jensen, 2013; Kerns et al, 2013) are all factors that have been reported to influence sexually related symptoms to various degrees. In addition, many prostate-cancer survivors use substances like sildenafil to compensate limitations in sexual performance, which also may cause confusion about the extent of an actual dysfunction (Incrocci and Jensen, 2013).

Pre-treatment erectile function is one of the most important factors predicting post-treatment function (Roach et al, 2010; Budaus et al, 2012; Hoppe et al, 2012; Keller et al, 2012; Incrocci and Jensen, 2013; Mirza et al, 2011). Although the structures most critical for sexual dysfunction after radiation therapy have not yet been conclusively determined, one recommendation is to keep the mean dose to $95 \%$ of the penile bulb volume to $<50 \mathrm{~Gy}$ (Roach et al, 2010). There is also evidence that intensity-modulated radiation therapy result in less sexual toxicity than threedimensional conformal radiation therapy (Mirza et al, 2011; Keller et al, 2012).

The purpose of this work was to provide a comprehensive overview of sexual symptoms after radiation therapy for prostate cancer as reported by sexually active long-term survivors and to relate these to symptom occurrence among non-pelvic-irradiated men from the general population. Our goal was to identify those persisting lower-grade symptoms that are likely to be a consequence of radiation therapy before the intensity-modulated radiation therapy era and which potentially can be the candidate symptoms to be avoided in modern prostate cancer radiation therapy to improve sexual health for future long-term survivors.

\section{MATERIALS AND METHODS}

The men included in this work constitute a subset of a larger study with the purpose to survey late effects after radiation therapy in prostate cancer survivors. Details on this cohort have been reported previously (Alsadius et al, 2011; Olsson et al, 2013), but will be summarized below.

Briefly, 1007 men had been consecutively treated for localized prostate cancer at the Sahlgrenska University Hospital in Gothenburg, Sweden, from 1993 to 2003. The survivors had received primary or salvage external beam radiation therapy $(\mathrm{EBRT})$, or primary EBRT in combination with BT $(\mathrm{EBRT}+\mathrm{BT})$. Among them, 985 met the eligibility criteria (no metastatic disease, age below 80 years, sufficient knowledge of Swedish (reading and understanding), and being a Swedish resident at the time of followup) and had agreed to participate in a questionnaire study surveying symptoms including sexual dysfunction after prostate cancer radiation therapy. Altogether, 874 returned a filled-in questionnaire. For the original study, a population-based reference group of 332 non-pelvic-irradiated prostate-cancer-free men, matched for age and residency, were recruited from the Swedish Total Population Register to provide symptom background rates, that is, the symptom occurrence in men from the general population. To be included in the present analysis, survivors and reference men also had to be free of diabetes mellitus and had to admit to being sexually active, including own stimulus, at the time of filling in the questionnaire.

The original study had been approved by the Regional Ethics Committee in Gothenburg, Sweden, and all participants gave written consent.
Treatment. The men receiving primary or salvage EBRT had usually been prescribed a total dose of 70 Gray (Gy) at 2 Gy per fraction (Pettersson et al, 2013). The majority of the men receiving EBRT in combination with BT had been prescribed an EBRT dose of $50 \mathrm{~Gy}$ at $2 \mathrm{~Gy}$ per fraction and a BT dose of $20 \mathrm{~Gy}$ in two $10 \mathrm{~Gy}$ fractions separated by 2 weeks. Both treatments were delivered during a 7-week period.

External beam radiation therapy was individually planned based on computed tomography (CT) imaging with the patient in a supine treatment position and with a low concentration of contrast in the bladder. No systematic instruction regarding bladder or rectal filling before CT scanning was employed. The planning target volume was defined as the prostate with a $20-\mathrm{mm}$ margin in all directions except posteriorly where the margin was $15 \mathrm{~mm}$ or no more than half of the rectum area. For prostatectomized patients, the planning target volume was defined similarly but with the original location of the prostate gland replaced by the postoperative prostatic region. A conformal isocentric three-field technique using one anterior and two lateral wedged fields was used for all patients. The treatment was delivered with 11 or $15 \mathrm{MV}$ photon beam quality and the dose was prescribed to the centre of the planning target volume according to the recommendations by the International Commissions on Radiation Units and Measurements (ICRU, 1999).

High-dose rate BT was also individually planned and based on transrectal ultrasound imaging with the patient in a lithotomy position. The planning target volume was defined as the prostate with a $2-\mathrm{mm}$ margin in all directions except cranially and caudally. The dose distribution was optimized by determining the number of needles, needle positions, and dwell times for the source within each needle. The objective of BT was to cover the planning target volume with the prescription dose while keeping the urethral absorbed dose below 120\%. Typically, 11-15 needles were manually inserted through a perineum template and the treatment was delivered using a high-dose rate ${ }^{192} \mathrm{Ir}$ source.

Questionnaire. Toxicity data for survivors and the reference men were taken from a study-specific questionnaire containing 165 detailed questions on symptoms associated with the gastrointestinal, genitourinary, and bony regions of the pelvis as well as questions on quality of life and sexuality, demographics, additional treatments, and co-morbidities (Alsadius et al, 2011). The questionnaire was constructed and validated according to the well-founded method established at the Divisions of Clinical Cancer Epidemiology at the University of Gothenburg in Göteborg and Karolinska Institutet in Stockholm, Sweden (Bergmark et al, 1999; Steineck et al, 2002a; Steineck et al, 2002b; Kreicbergs et al, 2004). Briefly, symptoms are identified after in-depth interviews with cancer survivors and operationalized into detailed questions (one atomized, 'conceptually clean', symptom per question) that are verified with individuals of the patient cohort under study to make sure that the questions are correctly understood and that relevant symptoms are included. Following a pilot study, where the questionnaire is tested for participation rate, logistics, frequency of missing answers, and may undergo additional adjustments, the main study is conducted as a cross-sectional postal questionnaire study.

For this work, we used a subset of 16 questions that reflect physical sexual symptoms concerning erectile function, libido, orgasm, and seminal fluid. There were 17 additional questions concerning quality-of-life issues relating to sexual symptoms and technical and medical aids to improve erection, but these will be subjects of future publications.

Statistics. To distinguish potentially different effects by radiation therapy regimens for prostate cancer on sexual toxicity, the survivors were analysed in three groups based on if they had had undergone primary EBRT, EBRT and $\mathrm{BT}(\mathrm{EBRT}+\mathrm{BT})$, or salvage 
EBRT. To quantify the occurrence of symptoms in each of these groups, symptom prevalence for a group of survivors as well as for the reference group were calculated as the fraction of individuals reporting a given symptom among the total number of individuals answering the question, missing answers excluded. To identify potentially radiation-induced symptoms, prevalence ratios with 95\% confidence intervals (CIs) were calculated as the ratio between the prevalence for a survivor group and the prevalence for the reference group. Age, pre-treatment sexual function, smoking, and hormonal treatment, previously reported to impact sexual function (Roach et al, 2010; Budaus et al, 2012), were included to provide adjusted prevalence ratios (or adjusted odds ratios if motivated by algorithm non-convergence; odds ratio calculated as the ratio between the odds for the survivor group and the odds for the reference group, odds calculated as the fraction of the prevalence ratio and 1 -the prevalence ratio). Pre-treatment sexual function was assessed by the question 'Did you have a weak erection before being diagnosed with prostate cancer?' with the answering categories 'no' and 'yes'. Smoking status was defined as never having smoked or as being a current or a former smoker. Hormonal treatment was defined as a positive response to removal of testicles at any time because of prostate cancer or treatment with anti-androgen or gonadotropin-releasing hormone $(\mathrm{GnRH})$ during the 6 months foregoing the time point of answering the questionnaire.

To illustrate potential effects by age and by time to follow-up on the investigated symptoms, we further analysed each survivor group in more detail. For age, survivors were divided into three clinically relevant subgroups with respect to age at study: younger than $60,60-70$ and older than 70 years of age. For time to follow-up, survivors were divided into four equally sized subgroups: shorter than 3 years, 3-5 years, 5-7.5 years, and longer than 7.5 years.

The men were asked to assess symptoms during the 6 months preceding the time point at which the questionnaire was answered. Analyses were performed with SAS 9.3 for Windows (SAS Institute Inc., Cary, NC, USA); the FREQ and the GENMOD Procedures for unadjusted and adjusted ratios, respectively. A two-sided $P<0.05$ or $95 \%$ CIs not including 1.0 were considered statistically significant.

\section{RESULTS}

When removing men with diabetes $(N=86)$ and sexually inactive men $(N=270)$ from the 874 men who had returned a filled-in questionnaire in the original study, data from 518 eligible survivors and 155 reference men were available for the analyses of this work. This meant that 270 out of $788(34 \%)$ of the non-diabetic men reported being not sexually active, including own stimulus. In reference men, corresponding numbers were 49 out of 204 (24\%) meaning that not being sexually active was almost one and a half times as common in survivors as in reference men (prevalence ratio: $1.4,95 \% \mathrm{CI}$ : $1.1-1.9, P=0.008$ ). Of the survivors, 165 men were treated with primary EBRT, 229 men with EBRT + BT and 124 men with salvage EBRT after prostatectomy.

Selected demographic characteristics are shown in Table 1. The median time to follow-up for the prostate cancer survivors was 5 years, range 1-14 years. The men treated with primary EBRT had a longer time to follow-up than men from the other treatment groups (6 years $v s 4-5$ years; $P<0.001$ ) and were also older (72 years vs 67-69 years; $P<0.001$ ). Hormonal treatment was reported by 23 out of 165 men (14\%) in the primary EBRT group, 19 out of $229(8 \%)$ in the EBRT + BT group and 29 out of 124 men $(13 \%)$ in the salvage EBRT group. None of the reference men reported having undergone hormonal treatment.

Sexual symptoms. Statistically significantly higher prevalence ratios with respect to reference men were found for 9 of the 16 investigated symptoms in the primary EBRT group, and for 10 symptoms in both the EBRT + BT group and the salvage EBRT group (Table 2). Differences in symptom profiles between the three treated groups concerned orgasm-related symptoms (questions 8, 12 , and 14).

The question reflecting reduced amount of seminal fluid following ejaculation (question 10) had the highest prevalence ratio in all the three groups. Of the prostate cancer survivors, 145 out of $387(37 \%)$ reported having no seminal fluid following ejaculation compared with 1 out of $144(1 \%)$ of the reference men. The second highest prevalence ratio in the EBRT group as well as the EBRT + BT group was found for the question reflecting quality of erection (question 3 ) with the quality never being sufficient for intercourse four-fold increased in survivors compared with reference men. In the salvage EBRT group, the second highest prevalence ratio was found for the question reflecting the ability to get an erection without medication or technical aids (question 1) with absence of erection being sevenfold increased in survivors compared with reference men. Adjusting for age, pre-treatment sexual function, smoking, and hormonal treatment did not change the overall symptom profiles (data not shown) and in the following sections we, therefore, report the unadjusted results.

Table 1. Demographic characteristics of prostate cancer survivors and reference men

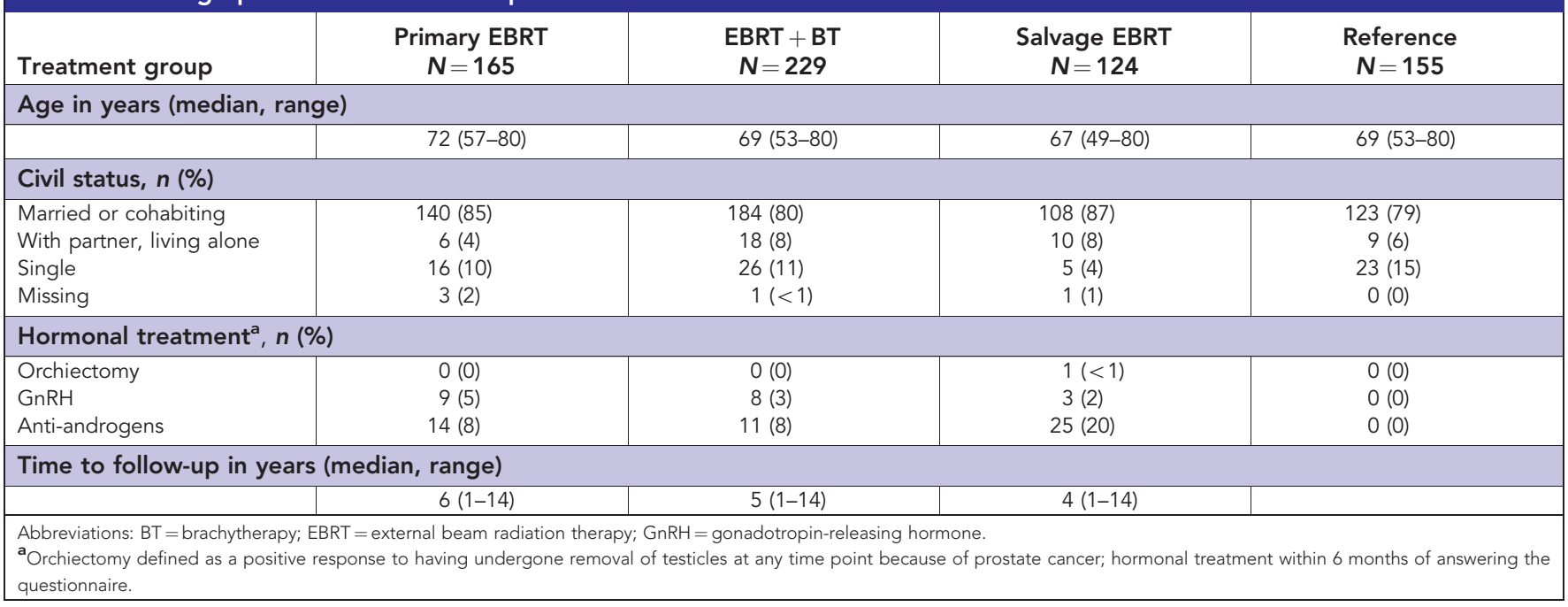


Table 2. Prevalence and prevalence ratios of sexual symptoms in prostate cancer survivors and reference men

\begin{tabular}{|c|c|c|c|c|}
\hline Treatment group & $\begin{array}{c}\text { Primary EBRT } \\
\quad N=165\end{array}$ & $\begin{array}{c}E B R T+B T \\
N=229\end{array}$ & $\begin{array}{l}\text { Salvage EBRT } \\
\quad N=124\end{array}$ & $\begin{array}{c}\text { Reference } \\
N=155\end{array}$ \\
\hline Symptom ${ }^{a}$ & $\begin{array}{c}n / N(\%) \\
\operatorname{PR}(95 \% \mathrm{Cl})\end{array}$ & $\begin{array}{c}n / N(\%) \\
\operatorname{PR}(95 \% \mathrm{Cl})\end{array}$ & $\begin{array}{c}n / N(\%) \\
\operatorname{PR}(95 \% \mathrm{Cl})\end{array}$ & $\begin{array}{c}n / N(\%) \\
\operatorname{PR}(95 \% \mathrm{Cl})\end{array}$ \\
\hline \multicolumn{5}{|c|}{ 1. Ability to get an erection without medication or technical aids } \\
\hline No & $\begin{array}{r}43 / 160(27) \\
3.1(1.7-5.6)\end{array}$ & $\begin{array}{r}51 / 226(23) \\
2.6(1.5-4.6) \\
\end{array}$ & $\begin{array}{c}70 / 124(57) \\
6.6(3.8-11.3)\end{array}$ & $\begin{array}{l}\text { 13/151 (9) } \\
\text { Reference }\end{array}$ \\
\hline \multicolumn{5}{|c|}{ 2. Ability to get an erection with medication or technical aids } \\
\hline No & $\begin{array}{c}11 / 42(26) \\
1.0(0.4-2.5)\end{array}$ & $\begin{array}{c}9 / 84(11) \\
0.4(0.2-1.1)\end{array}$ & $\begin{array}{c}12 / 61(20) \\
0.8(0.3-1.9)\end{array}$ & $\begin{array}{l}\text { 6/24 (25) } \\
\text { Reference }\end{array}$ \\
\hline \multicolumn{5}{|c|}{ 3. Quality of erection at sexual activity } \\
\hline Never sufficient for intercourse & $\begin{array}{r}48 / 136(35) \\
4.1(2.3-7.4)\end{array}$ & $\begin{array}{r}64 / 202(32) \\
3.7(2.1-6.6)\end{array}$ & $\begin{array}{c}57 / 109(52) \\
6.1(3.5-10.8)\end{array}$ & $\begin{array}{l}12 / 140(9) \\
\text { Reference }\end{array}$ \\
\hline \multicolumn{5}{|c|}{ 4. Quality of nocturnal erection } \\
\hline Never sufficient for intercourse & $\begin{array}{l}107 / 161(67) \\
1.8(1.4-2.3)\end{array}$ & $\begin{array}{l}141 / 225(63) \\
1.7(1.4-2.2)\end{array}$ & $\begin{array}{l}101 / 124(82) \\
2.2(1.8-2.8)\end{array}$ & $\begin{array}{l}\text { 54/149 (36) } \\
\text { Reference }\end{array}$ \\
\hline \multicolumn{5}{|c|}{ 5. Loss of erection during sexual activity } \\
\hline Half the time or more & $\begin{array}{r}49 / 121(41) \\
2.1(1.4-3.2)\end{array}$ & $\begin{array}{r}78 / 184(42) \\
2.2(1.5-3.3)\end{array}$ & $\begin{array}{c}32 / 91(35) \\
1.8(1.2-2.9) \\
\end{array}$ & $\begin{array}{l}\text { 26/136 (19) } \\
\text { Reference }\end{array}$ \\
\hline \multicolumn{5}{|l|}{ 6. Painful erections } \\
\hline Monthly or more often & $\begin{array}{c}5 / 119(4) \\
1.4(0.4-5.1)\end{array}$ & $\begin{array}{c}5 / 182(3) \\
0.9(0.3-3.3)\end{array}$ & $\begin{array}{c}4 / 79(5) \\
1.7(0.4-6.5)\end{array}$ & $\begin{array}{l}4 / 133(3) \\
\text { Reference }\end{array}$ \\
\hline \multicolumn{5}{|l|}{ 7. Amount of sexual desire } \\
\hline None & $\begin{array}{c}14 / 158(9) \\
2.7\left(1.0^{\mathbf{b}}-7.2\right)\end{array}$ & $\begin{array}{r}10 / 224(5) \\
1.3(0.5-3.8)\end{array}$ & $\begin{array}{c}11 / 124(9) \\
2.7\left(1.0^{b}-7.5\right)\end{array}$ & $\begin{array}{l}5 / 150(3) \\
\text { Reference }\end{array}$ \\
\hline \multicolumn{5}{|l|}{ 8. Painful ejaculations } \\
\hline Any & $\begin{array}{c}12 / 127(10) \\
2.7\left(1.0^{b}-7.4\right)\end{array}$ & $\begin{array}{r}22 / 180(12) \\
3.5(1.3-8.9)\end{array}$ & $\begin{array}{c}12 / 73(16) \\
4.7(1.7-12.7) \\
\end{array}$ & $\begin{array}{l}5 / 142(4) \\
\text { Reference }\end{array}$ \\
\hline \multicolumn{5}{|c|}{ 9. Discomfortable but not painful, ejaculations } \\
\hline Any & $\begin{array}{c}6 / 124(5) \\
1.4(0.4-4.4)\end{array}$ & $\begin{array}{c}7 / 178(4) \\
1.1(0.4-3.5)\end{array}$ & $\begin{array}{c}1 / 68(2) \\
0.4(0.1-3.5)\end{array}$ & $\begin{array}{l}5 / 143(4) \\
\text { Reference }\end{array}$ \\
\hline \multicolumn{5}{|c|}{ 10. Amount of secretion or expulsion of semen following ejaculation } \\
\hline None & $\begin{array}{c}21 / 128(16) \\
23.6(3.2-173.2)\end{array}$ & $\begin{array}{c}60 / 186(32) \\
46.5(6.5-331.2)\end{array}$ & $\begin{array}{c}64 / 73(88) \\
126.2(17.8-891.8) \\
\end{array}$ & $\begin{array}{l}1 / 144(1) \\
\text { Reference }\end{array}$ \\
\hline \multicolumn{5}{|l|}{ 11. Blood in semen } \\
\hline Any & $\begin{array}{c}3 / 113(3) \\
1.9(0.3-11.2)\end{array}$ & $\begin{array}{c}5 / 141(4) \\
2.5(0.5-12.9)\end{array}$ & $\begin{array}{l}\text { 0/19 (0.0) } \\
\text { n.a. }\end{array}$ & $\begin{array}{l}\text { 2/143 (1) } \\
\text { Reference }\end{array}$ \\
\hline \multicolumn{5}{|c|}{ 12. Orgasm at sexual activity } \\
\hline Less than half the time & $\begin{array}{l}40 / 135(29.6) \\
2.3(1.4-3.9)\end{array}$ & $\begin{array}{l}46 / 194(23.7) \\
1.9(1.1-3.1)\end{array}$ & $\begin{array}{l}21 / 103(20.4) \\
1.6(0.9-2.9)\end{array}$ & $\begin{array}{l}\text { 18/142 (13) } \\
\text { Reference }\end{array}$ \\
\hline \multicolumn{5}{|c|}{ 13. Sensation of orgasm at sexual activity weaker than normal } \\
\hline Half the time or more & $\begin{array}{l}61 / 132(46.2) \\
3.4(2.2-5.4)\end{array}$ & $\begin{array}{l}67 / 186(36.0) \\
2.7(1.7-4.2)\end{array}$ & $\begin{array}{l}31 / 97(32.0) \\
2.4(1.4-3.9)\end{array}$ & $\begin{array}{l}\text { 19/140 (14) } \\
\text { Reference }\end{array}$ \\
\hline \multicolumn{5}{|c|}{ 14. Pain in genital area after orgasm } \\
\hline Any & $\begin{array}{r}7 / 131(5.3) \\
1.5(0.5-4.7)\end{array}$ & $\begin{array}{l}12 / 188(6.4) \\
1.9(0.7-5.1)\end{array}$ & $\begin{array}{l}10 / 98(10.2) \\
3.0\left(1.0^{c}-8.4\right)\end{array}$ & $\begin{array}{l}5 / 145(4) \\
\text { Reference }\end{array}$ \\
\hline \multicolumn{5}{|c|}{ 15. Sensation of orgasm at sexual activity satisfying } \\
\hline No & $\begin{array}{l}43 / 129(33.3) \\
3.6(2.0-6.4)\end{array}$ & $\begin{array}{l}49 / 189(25.9) \\
2.8(1.6-4.9)\end{array}$ & $\begin{array}{l}20 / 99(20.2) \\
2.2(1.1-4.2)\end{array}$ & $\begin{array}{l}\text { 13/140 (9) } \\
\text { Reference }\end{array}$ \\
\hline \multicolumn{5}{|c|}{ 16. Number of sexual intercourses } \\
\hline Zero & $\begin{array}{l}63 / 160(39.4) \\
1.8(1.3-2.6)\end{array}$ & $\begin{array}{l}72 / 219(32.9) \\
1.5(1.1-2.2)\end{array}$ & $\begin{array}{l}49 / 120(40.8) \\
1.9(1.3-2.8)\end{array}$ & $\begin{array}{l}\text { 31/144 (22) } \\
\text { Reference }\end{array}$ \\
\hline \multicolumn{5}{|c|}{ 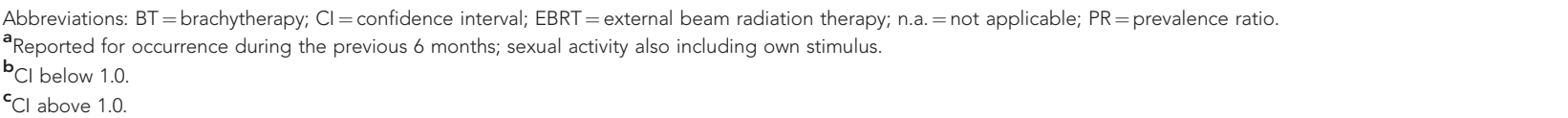 } \\
\hline
\end{tabular}

Influence of age on sexual symptoms. The influence of age on symptoms with statistically significant prevalence ratios between survivors and reference men is shown by treatment group in
Supplementary Figure 1. When dividing each survivor group into age intervals of younger than 60 years, between 60 and 70 years, and older than 70 years, there was one symptom relating to erectile 
dysfunction where the symptom prevalence varied with age within a treatment group (question 5, Figure 1). For this question, the symptom prevalence in survivors of the primary EBRT group was decreased for survivors aged above 70 years compared with the

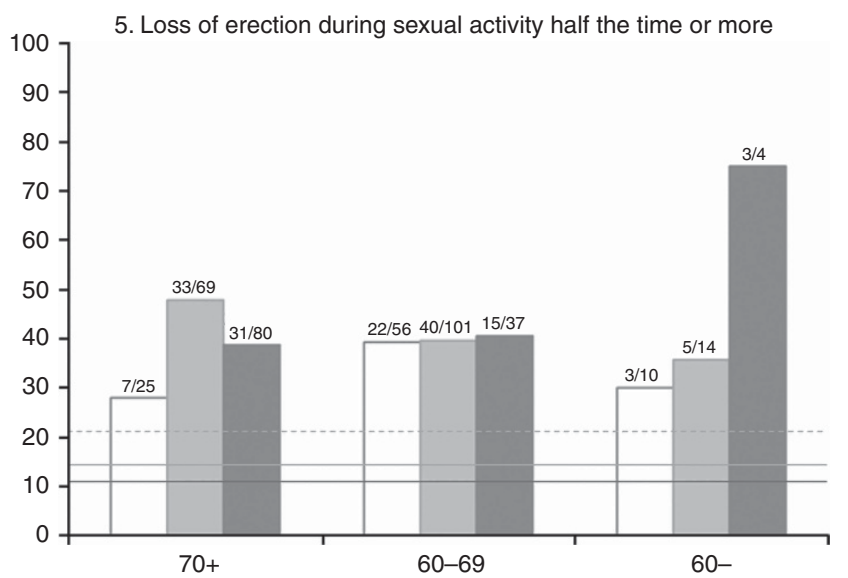

Figure 1. The effect of age on symptom prevalence for prostate cancer survivors displayed by radiation therapy regimen. Ages younger than 60 years, between 60 and 70 years, and above 70 years displayed on the $x$ axis and symptom prevalence on the $y$ axis. Primary external beam radiation therapy (EBRT) displayed in the dark grey bars, EBRT in combination with brachytherapy (EBRT+BT) displayed in the light grey bars, and salvage EBRT displayed in the white bars; the dotted line is the symptom prevalence in reference men younger than 60 years, the light grey line in reference men $60-70$ years, and the dark grey line in reference men older than 70 years. The number preceding the symptom refers to the associated question number in Table 2.

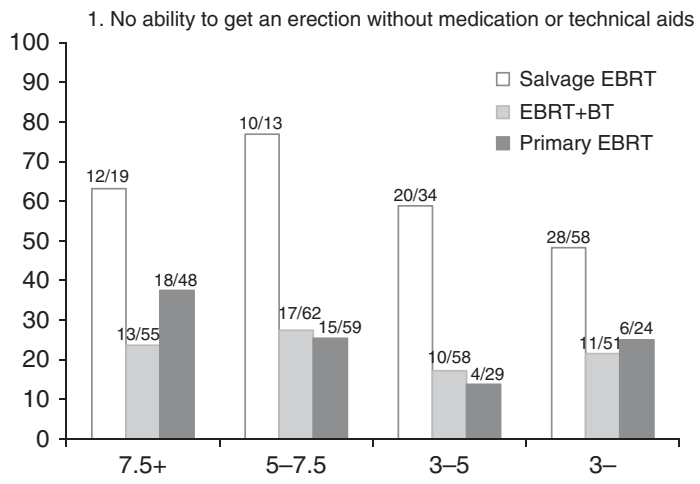

10. No secretion or expulsion of semen following ejaculation

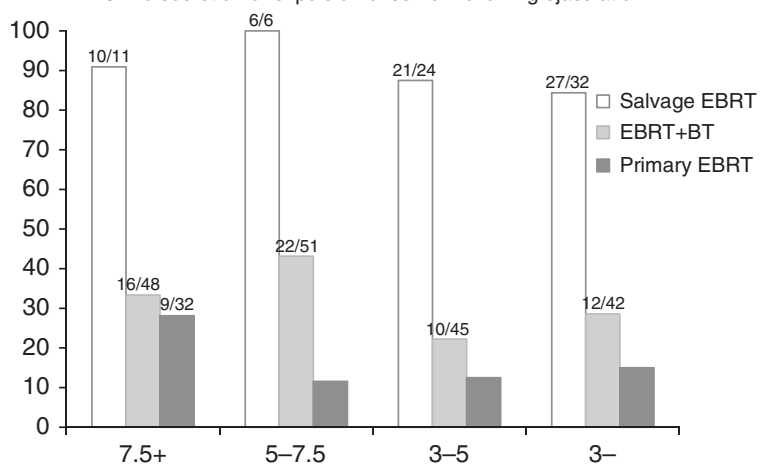

survivors aged less than 60 years (prevalence ratio: $0.5,95 \%$ CI: $0.3-1.0, P=0.040$ ). However, with respect to the reference men, this symptom was statistically significantly more prevalent only in survivors aged $60-70$ years (prevalence ratio: $2.5,95 \%$ CI: $1.3-4.8$, $P=0.008)$ and borderline statistically significantly in survivors younger than 60 years (prevalence ratio: 6.8, 95\% CI: $1.0-46.6, P=0.053)$.

Influence of time to follow-up on sexual symptoms. The influence of time to follow-up by treatment on the symptoms with statistically significant prevalence ratios between survivors and reference men is shown in Supplementary Figure 2. When dividing each survivor group into time to follow-up intervals of shorter than 3 years, 3-5 years, 5-7 years, and longer than 7.5 years, there were four symptoms where the symptom prevalence varied with time to follow-up within a treatment group (Figure 2). Two symptoms related to erectile dysfunction (questions 1 and 5), one to orgasm (question 12), and one to seminal fluid (question 10).

For erectile dysfunction, the symptom prevalence for question 1 was increased in survivors of the primary EBRT group for followup longer than 7.5 years compared with follow-up 3-5 years (prevalence ratio: $2.7,95 \%$ CI:1.0-7.2, $P=0.046$ ). The increasing trend was similar for survivors in the salvage EBRT group but for follow-up 5-7.5 years compared with follow-up shorter than 3 years (prevalence ratio: 1.5, 95\% CI:1.1-2.4, $P=0.022$ ). With respect to the reference men, this symptom was statistically significantly more prevalent for all time intervals except for 3-5 years in the primary EBRT group and for all time intervals in the salvage EBRT group (data not shown). The symptom prevalence for question 5 was decreased in survivors of the EBRT + BT group for follow-up longer than 7.5 years compared with follow-up shorter than 3 years (prevalence ratio: 0.6, 95\% CI: $0.4-1.0, P=0.045)$. With respect to the reference men, this

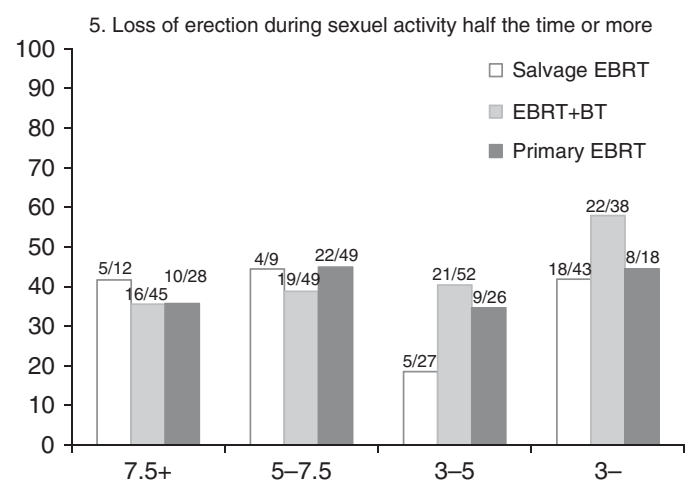

12. Orgesm at sexuel activity less than half the time

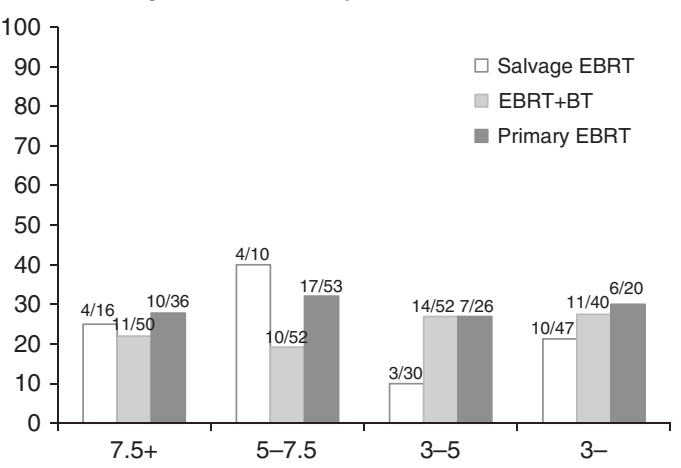

Figure 2. The effect of time since radiation therapy on symptom prevalence for prostate cancer survivors displayed by radiation therapy regimen. Time to follow-up in intervals shorter than 3 years, 3-5 years, 5-7.5 years and longer than 7.5 years displayed on the $x$ axis and symptom prevalence on the $y$ axis. Primary external beam radiation therapy (EBRT) displayed in the dark grey bars, EBRT in combination with brachytherapy $(E B R T+B T)$ displayed in the light grey bars, and salvage EBRT displayed in the white bars; the dotted line is the prevalence in reference men. The numbers preceding each symptom refer to the associated question number in Table 2. 
symptom was statistically significantly more prevalent for all time intervals (data not shown).

For orgasm, the symptom prevalence for question 12 was increased in survivors of the salvage EBRT for follow-up 5-7.5 years compared with 3-5 years follow-up (prevalence ratio: 4.0, 95\% CI: 1.1-14.9, $P=0.039$ ). However, with comparison with the reference men, this symptom was only more prevalent in survivors followed-up 5-7.5 years (prevalence ratio: 3.2, 95\% CI: $1.3-7.6, P=0.001$ ).

For seminal fluid, the symptom prevalence for question 10 for survivors in the EBRT + BT group for follow-up was increased for follow-up 5-7.5 years compared with follow-up 3-5 years (prevalence ratio: $1.9,95 \% \mathrm{CI}: 1.0-3.6, P=0.039$ ). With respect to the reference men, this symptom was statistically significantly more prevalent for all time intervals (data not shown).

\section{DISCUSSION}

We found that up to ten symptoms on erectile function, libido, orgasm, and seminal fluid occurred more frequently in sexually active survivors treated with radiation therapy for prostate cancer than in a comparable group of non-treated men of the general population. Erectile dysfunction was influenced by both age and time to follow-up, whereas symptoms relating to orgasm and seminal fluid were influenced by time to follow-up only. Not being sexually active was almost one and a half times as common in survivors as in reference men.

To our knowledge, this is the first study that describes the impact of various radiation therapy strategies on patient-reported sexual toxicity in sexually active prostate cancer survivors and at the same time acknowledges the majority of the factors previously reported to influence these symptoms. The symptom profiles of the three investigated treatment groups were surprisingly similar but differed with respect to symptoms relating to erectile dysfunction. There is an up to $70 \%$ occurrence of erectile dysfunction in men treated with EBRT depending on the method of assessment (physician-reported leading to lower numbers than patientreported) and time to follow-up (Keller et al, 2012; Incrocci and Jensen, 2013). Vascular impairment and corporal fibrosis is associated with EBRT and is reported to result in lower symptom prevalence than the neurological damage that is associated with surgery (Hoppe et al, 2012; Keller et al, 2012). The results of this work are in line with these previous publications with the symptom prevalence in both the primary EBRT group and the EBRT + BT group being lower than the symptom prevalence in the salvage EBRT group (25-65\% vs 35-80\%, respectively). It has previously been reported that differences in symptom occurrence between primary EBRT and surgery level out with longer time to follow-up (Resnick et al, 2013), but this was not reflected in the symptom prevalence of the primary and salvage EBRT groups of this work. Furthermore, data on sexual toxicity after adding BT to EBRT suggest an increase in symptom prevalence (Incrocci and Jensen, 2013). This can for instance be attributed to the increased normal tissue damage that can be expected at higher doses per fraction as typically given in BT compared with EBRT or by effects relating to the surgical procedure when placing the implant needles for BT. The symptom prevalence of our primary EBRT group were, however, similar to that of our EBRT + BT group.

Erectile dysfunction is the sexual symptom that has been most investigated so far (Roach et al, 2010; Mirza et al, 2011; Budaus et al, 2012; Hoppe et al, 2012; Keller et al, 2012; Incrocci and Jensen, 2013), and it is included in common toxicity scoring systems that address sexual symptoms after radiation therapy such as the Late Effect Normal Tissue Subjective Objective Management Analytic (LENT SOMA tables, 1995) and the Expanded Prostate Cancer Index Composite (EPIC) questionnaire (Wei et al, 2000). Erectile dysfunction is reported to have a maximum drop at 3 months post-radiation therapy with a recovery at 1 year, which stays stable at 2 and 3 years (Budaus et al, 2012; Incrocci and Jensen, 2013); it has also been reported to worsen with time, primarily in men 60 years or younger (Hoppe et al, 2012; Resnick et al, 2013). Among our investigated symptoms relating to erectile dysfunction, we found that the prevalence of losing erection during sexual activity (question 5) decreased with longer time to follow-up in the EBRT + BT groups but not in the other two treatment groups. However, with respect to age and the background symptom rate, this decline in symptom prevalence was only statistically significant in survivors aged less than 70 years suggesting that this may be more of a problem in younger men treated with the combination of EBRT and BT. We also found that not being able to get an erection without medication or technical aids (question 1) increased with longer time to follow-up in survivors treated with primary or salvage EBRT. Together, these findings illustrate the importance of addressing erectile dysfunction from many perspectives, including radiation therapy strategies, to get a wider understanding of its temporal trajectory.

Symptoms relating to orgasm and seminal fluid have gotten less attention in the literature on radiation-induced sexual toxicity than erectile dysfunction. We found that the prevalence of not achieving orgasm at sexual activity (question 12) doubled with longer time to follow-up in the salvage EBRT group and that the prevalence of missing seminal fluid (question 10) doubled with longer time to follow-up in the EBRT + BT group. However, when assessing these findings in more detail, including our results on erectile dysfunction, the orgasm-related symptom turned out to be statistically significantly increased with respect to reference men for 5-7.5 years follow-up only. It has previously been pointed out that the lack of comparison with symptom prevalence in a non-treated reference group may overestimate the contribution of radiation therapy in many studies (Resnick et al, 2013). Our results further illustrate the importance of addressing background symptom rates when working with the kinds of data as presented here.

The main strength of this work is that we used sexually active men from a large study population with a long time to follow-up and a non-treated matched reference group from the general population to identify radiation-related sexual symptoms after prostate cancer radiation therapy. The Swedish Total Population Register allowed us to follow-up all eligible men and, together with a high study participation and questionnaire response rate, the risk of selection-induced problems could be reduced. The use of a postal questionnaire also minimized the risk of interviewer-related problems. We could account for many factors that have previously been described to be associated with sexual dysfunction such as age, diabetes mellitus, pre-treatment sexual function, radiation therapy regimen, and time to follow-up. We also aimed to investigate the impact of hormonal treatment on radiation-related sexual symptoms, hormonal treatment being defined as a positive response to removal of testicles at any time because of prostate cancer or treatment with anti-androgen or gonadotropin-releasing hormone $(\mathrm{GnRH})$ during the 6 months foregoing the time point of answering the questionnaire. However, our data did not allow us to investigate this as the groups became too small when stratifying for hormonal treatment. With that said, our results reflect nonhormonally treated men more than men undergoing hormonal treatment. A limitation with this work is that our results were based on the information from a fairly homogenous group of men with respect to age and ethnicity. They were also treated at one centre in Sweden during a specific time period. This has to be kept in mind when relating our results to men of other age groups, ethnicities, and other settings. Furthermore, our reported symptom prevalence was calculated for all survivors by radiation therapy strategy and because of this averaged over time to follow-up. This may have limited our ability to detect radiation-induced symptoms to some extent although we found that the majority of symptoms 
remained stable over time. Although this study population allows for analyses on the potential effect of medical substances and technical aids on sexual symptoms, we found this to be outside the scope of the presented work. For the same reason, we did not analyse the relationship between psychological factors and sexual symptoms. All these aspects need to be further investigated and will be reported in future publications.

In conclusion, we found that several radiation-related symptoms on erectile function, libido, orgasm, and seminal fluid existed after radiation therapy for prostate cancer and that prostate cancer survivors reported to be less sexually active than comparable nonpelvic-irradiated men of the general population. The majority of these symptoms remain stable in prevalence even 7 years post treatment. Although symptom profiles were similar between radiation therapy strategies, the actual symptom prevalence varied. Together, our results suggest that acknowledging different treatment regimens and not only focusing on erectile dysfunction can assist in increasing our understanding of relationships between dose and sexual toxicity. Together with objective measures to quantify sexual dysfunction, for example, the 'stamp test' for erectile dysfunction (Keller et al, 2012), psychological effects such as anxiety and depression may be removed and together with patient's perspective of having the symptoms identified in this work as well as by others, the presented results can help to decide which symptoms to avoid in future prostate cancer radiation therapy.

\section{ACKNOWLEDGEMENTS}

The authors would like to thank all the men who participated in the study, as well as the staff at the Sahlgrenska University Hospital who were involved in patient care and data collection. This work was supported by the Swedish Cancer Society, the King Gustav V Jubilee Clinic Cancer Foundation in Göteborg, the Swedish state under the ALF agreement in Göteborg and Stockholm. Support from the Assar Gabrielsson Foundation, Tore Nilssons Foundation, and 'Syskonen Svenssons fond för medicinsk forskning' are also gratefully acknowledged.

\section{CONFLICT OF INTEREST}

The authors declare no conflict of interest.

\section{REFERENCES}

Alsadius D, Hedelin M, Johansson KA, Pettersson N, Wilderäng U, Lundstedt D, Steineck G (2011) Tobacco smoking and long-lasting symptoms from the bowel and the anal-sphincter region after radiotherapy for prostate cancer. Radiother Oncol 101(3): 495-501.

Bergmark K, Åvall-Lundqvist E, Dickman PW, Henningsohn L, Steineck G (1999) Vaginal changes and sexuality in women with a history of cervical cancer. N Engl J Med 340(18): 1383-1389.

Budaus L, Bolla M, Bossi A, Cozzarini C, Crook J, Widmark A, Wiegel T (2012) Functional outcomes and complications following radiation therapy for prostate cancer: a critical analysis of the literature. Eur Urol 61(1): 112-127.

De Sousa A, Sonavane S, Mehta J (2012) Psychological aspects of prostate cancer: a clinical review. Prostate Cancer Prostatic Dis 15(2): 120-127.

Haugnes HS, Melby B, Larsen KM, Langdal I, Rasi M, Bremnes RM (2012) Assessment of late urinary, bowel and sexual function after dose escalation from 70 to $76 \mathrm{~Gy}$ using image-guided radiotherapy in curative treatment of prostate cancer. Scand J Urol Nephrol 46(2): 124-132.
Hoppe BS, Nichols RC, Henderson RH, Morris CG, Williams CR, Costa J, Marcus Jr. RB, Mendenhall WM, Li Z, Mendenhall NP (2012) Erectile function, incontinence, and other quality of life outcomes following proton therapy for prostate cancer in men 60 years old and younger. Cancer 118(18): 4619-4626.

Incrocci L, Jensen PT (2013) Pelvic radiotherapy and sexual function in men and women. J Sex Med 10(Suppl 1): 53-64.

ICRU (1999) Prescribing, Recording and Reporting Photon Beam Therapy. International Commissions on Radiation Units and Measurements (Supplement to ICRU Report 50): Bethesda, MD, USA. Report 62.

Keller LM, Buyyounouski MK, Sopka D, Ruth K, Klayton T, Pollack A, Watkins-Bruner D, Greenberg R, Price R, Horwitz EM (2012) Stamp test delivers message on erectile dysfunction after high-dose intensitymodulated radiotherapy for prostate cancer. Urology 80(2): 337-342.

Kerns SL, Stock R, Stone N, Buckstein M, Shao Y, Campbell C, Rath L, De Ruysscher D, Lammering G, Hixson R, Cesaretti J, Terk M, Ostrer H, Rosenstein BS (2013) A 2-stage genome-wide association study to identify single nucleotide polymorphisms associated with development of erectile dysfunction following radiation therapy for prostate cancer. Int $J$ Radiat Oncol Biol Phys 85(1): e21-e28.

Kreicbergs U, Valdimarsdottir U, Onelöv E, Henter JI, Steineck G (2004) Talking about death with children who have severe malignant disease. $N$ Engl J Med 351(12): 1175-1186.

LENT SOMA tables (1995) Radiother Oncol 35(1): 17-60.

Magli A, Giangreco M, Crespi M, Negri A, Ceschia T, De Giorgi G, Titone F, Parisi G, Fongione S (2012) Erectile dysfunction after prostate threedimensional conformal radiation therapy. Correlation with the dose to the penile bulb. Strahlenther Onkol 188(11): 997-1002.

Mirza M, Griebling TL, Wallace Kazer M (2011) Erectile dysfunction and urinary incontinence after prostate cancer treatment. Semin Oncol Nurs 27(4): 278-289.

Olsson CE, Pettersson N, Alsadius D, Wilderäng U, Tucker SL, Johansson KA, Steineck G (2013) Patient-reported genitourinary toxicity for long-term prostate cancer survivors treated with radiation therapy. Br J Cancer 108(10): 1964-1970.

Omerov P, Steineck G, Runeson B, Christensson A, Kreicbergs U, Pettersen R, Rubenson B, Skoogh J, Radestad I, Nyberg U (2013) Preparatory studies to a population-based survey of suicide-bereaved parents in Sweden. Crisis 34(3): 200-210.

Pettersson N, Olsson C, Tucker SL, Alsadius D, Wilderäng U, Johansson KA, Steineck G (2013) Urethral pain among prostate cancer survivors 1 to 14 years after radiation therapy. Int J Radiat Oncol Biol Phys 85(1): e29-e37.

Resnick MJ, Koyama T, Fan KH, Albertsen PC, Goodman M, Hamilton AS, Hoffman RM, Potosky AL, Stanford JL, Stroup AM, Van Horn RL, Penson DF (2013) Long-term functional outcomes after treatment for localized prostate cancer. $N$ Engl J Med 368(5): 436-445.

Roach 3rd M, Nam J, Gagliardi G, El Naqa I, Deasy JO, Marks LB (2010) Radiation dose-volume effects and the penile bulb. Int J Radiat Oncol Biol Phys 76(3 Suppl): S130-S134.

Steineck G, Bergmark K, Henningsohn L, al-Abany M, Dickman PW, Helgason A (2002a) Symptom documentation in cancer survivors as a basis for therapy modifications. Acta Oncol 41(3): 244-252.

Steineck G, Helgesen F, Adolfsson J, Dickman PW, Johansson JE, Norlen BJ, Holmberg L. Scandinavian Prostatic Cancer Group Study N (2002b) Quality of life after radical prostatectomy or watchful waiting. N Engl J Med 347(11): 790-796.

Steineck G, Hunt H, Adolfsson J (2006) A hierarchical step-model for causation of bias-evaluating cancer treatment with epidemiological methods. Acta Oncol 45(4): 421-429.

Wei JT, Dunn RL, Litwin MS, Sandler HM, Sanda MG (2000) Development and validation of the expanded prostate cancer index composite (EPIC) for comprehensive assessment of health-related quality of life in men with prostate cancer. Urology 56(6): 899-905.

This work is published under the standard license to publish agreement. After 12 months the work will become freely available and the license terms will switch to a Creative Commons AttributionNonCommercial-Share Alike 4.0 Unported License.

Supplementary Information accompanies this paper on British Journal of Cancer website (http://www.nature.com/bjc) 